\title{
Advanced Vibroscanning Method for Microhole Measurement - High speed and stability improvement of measurement technique-
}

\author{
Beom-Joon KIM*, Yoshimasa SAWAMOTO**, Takahisa MASUZAWA*, and Masatoshi FUJINO* \\ (Received on June 5, 1995) \\ *Institute of Industrial Science, The University of Tokyo \\ 7-22-1 Roppongi, Minato-ku, Tokyo 106, Japan \\ **I.I.S., The University of Tokyo (presently with Mitsubishi Heavy Industries, Ltd.)
}

Although many microparts, in particular, microholes, can be machined by EDM, it is difficult to measure the machined inner dimensions of the microhole. Therefore a new measurement method for microholes, the vibroscanning method, was developed and a high-speed measurement algorithm was improved. The principle of detection is based on sensing of the electrical contact between the inner surface of a hole and a vibrating probe. In this study, we investigated the influence of (i) probe materials, (ii) vibration frequency, and (iii) waveform, on measurement stability and accuracy in order to improve the VS method for measurement of microholes machined by EDM.

Key Words : microhole, measurement technique, WEDG, vibrating probe, contact reliability

\section{INTRODUCTION}

The recent development of EDM (electrical discharge machining) techniques and nonconventional machinings has led to the successful fabrication of microproducts. The trend toward higher precision and increasing miniaturization in a wide range of manufacturing activities has led to new requirements in machining, positioning, control and metrology, down to the nanometer scale. For example, the EDM machine has enabled the production of microholes with diameter ranging from $5 \mu \mathrm{m}$ to $100 \mu \mathrm{m}^{[1][2]}$.

On the other hand, when the problems involved in manufacturing are solved, it is necessary to inspect the fabricated products in order to improve their quality. Therefore, dimensional metrology is important in the field of micro-machining. Many new methods of measurement have been developed, so far. The STM (scanning tunneling microscope) and AFM (atomic force microscope) are well known advanced surface measurement systems.

However, it has been difficult to measure the inner dimensions of a microhole in many kinds of microproducts. In this paper, the expression "microhole" means that the hole diameter is below $500 \mu \mathrm{m}$. In particular, in the case of deep microholes, it is rather difficult to use microscopes, such as optical ones and STM for measurement in terms of measurement speed and fitness of equipment. Because of the difficulties described above, factory inspections of the inner dimensions of holes usually make use of limit pin gauges. This method yields only information on the narrowest diameter of a hole.

In order to overcome the above problem, a new measurement technique was presented for the first time by Masuzawa et al ${ }^{[3]}$. They developed the "vibroscanning method", where a microvibrating probe is used (hereafter referred to as the VS method). This method is nondestructive, and the principle of detection is based on the sensing of electrical contact. Moreover, they succeeded in improving the measurement speed up to 10 s per $500 \mu \mathrm{m}$ depth by developing a high-speed measurement algorithm ${ }^{[4]}$. In this paper, we introduce an improved algorithm for high-speed measurement, and two important parameters, probe material and vibration waveform, are investigated as regard their influences on the measurement reproducibility ${ }^{[5]}$. The results are expected to provide information for the selection of the most appropriate probe material and its optimal driving conditions.

\section{VS METHOD ${ }^{[3]}$}

The principle of the VS method is as follows. For inner-hole measurements, we carefully insert the probe into a hole while controlling the position of the 
table and the probe holder. While the probe is vibrating perpendicularly to the object surface with a narrow amplitude, an electric voltage is applied between the probe and the surface. When the distance between the probe and the surface is small enough so that the probe end (tip) contacts the surface, the electric loop of the sensing circuit closes. Since the probe is vibrating, the loop closure occurs intermittently. The contact time when the circuit closes per vibration period is defined as the "duty factor" (hereafter referred to as DF), and is expressed as

$\mathrm{DF}=\mathrm{a}$ contact time / one vibration period.

By determining DF and probe position data, we can calculate the distance between the probe and the surface, and the inner dimensions of a microhole can be measured precisely.

Figure 1 shows the system construction of the prototype VS equipment.

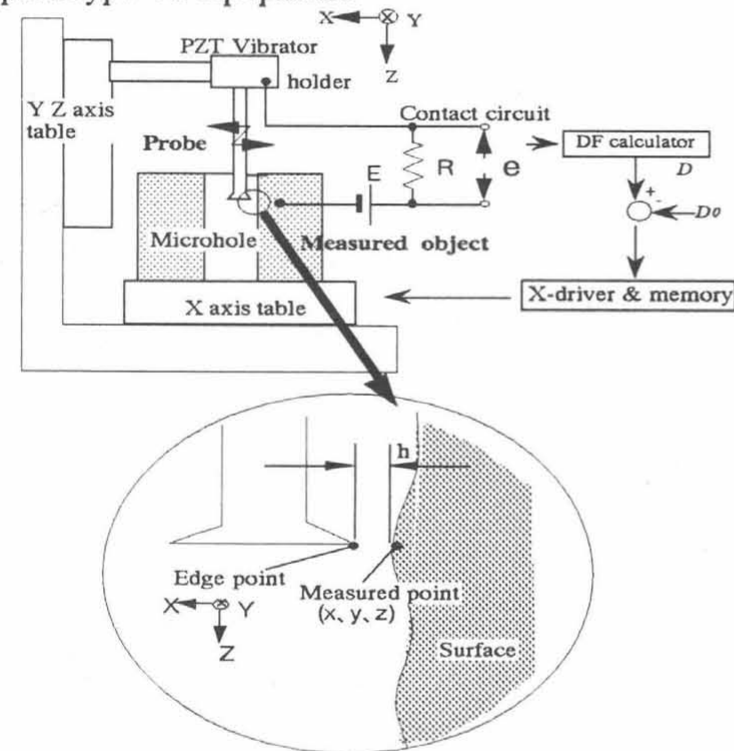

Fig.1 Detection principle and system construction of VS method.

\section{HIGH SPEED OF MEASUREMENT}

When the VS method was invented, the average value of DF was determined using the integral circuit of the second low-pass filter. Sawamoto et al. developed the digital detector of DF and a new measurement algorithm in order to reduce the measurement time ${ }^{[4]}$. By counting the digital gate signal of a basic pulse $(100 \mathrm{kHz})$ and the contact signal, we can scan a 500- $\mu \mathrm{m}$-deep microhole surface within a few seconds without determining the average value of DF.
Two algorithms have been developed for the VS method. The first one is based on "the control of the DF at a constant value" (hereafter referred to as the $\mathrm{CD}$ process). In this algorithm, the probe scans the surface profile while a feedback control system maintains the DF at a constant value, ensuring the constancy of the distance between the probe and the surface. Therefore, we can determine the inner dimensions from the position data of the probe at each moment. The second method is a "step scanning algorithm" (hereafter referred to as the SS process). This process was developed in order to increase the measurement speed. It is useful because the surface can be characterized in some bounds through only the variations of the DF from the relationship between DF and the probe position ${ }^{[4]}$. Therefore, since the profile can be calculated from only the changes of DF, we make the probe approach the surface only when DF is outside a certain range.

Figure 2 shows the principle of the measurement algorithms. In this figure, the traces of the scanning probe are shown.

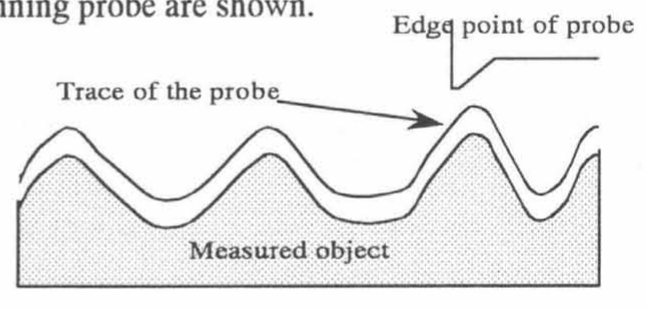

CD PROCESS

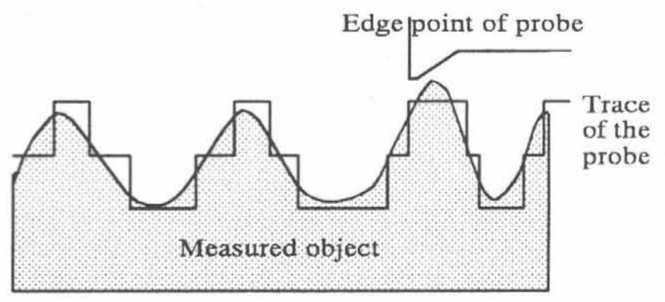

SS PROCESSS

Fig.2 Traces of scanning probe by two alguithms.

\section{EXPERIMENT}

In this study, under each set of conditions, we took more than 5 measurements from a standard specimen with surface roughness (Rmax) of $6.3 \mu \mathrm{m}$ using the $\mathrm{CD}$ process $(\mathrm{DF}=0.5)$. To ensure good reliability, the measurement was performed at about $25^{\circ} \mathrm{C}$ in a clean room.

\section{4-1. Influence of probe material}

To investigate the influence of the probe 
material on measurement, microprobes were made from six kinds of materials. All microprobes for the VS method were made by WEDG (wire electrodischarge grinding) ${ }^{[6]}$. The WEDG process and the shape of the probe are shown in Figure 3.
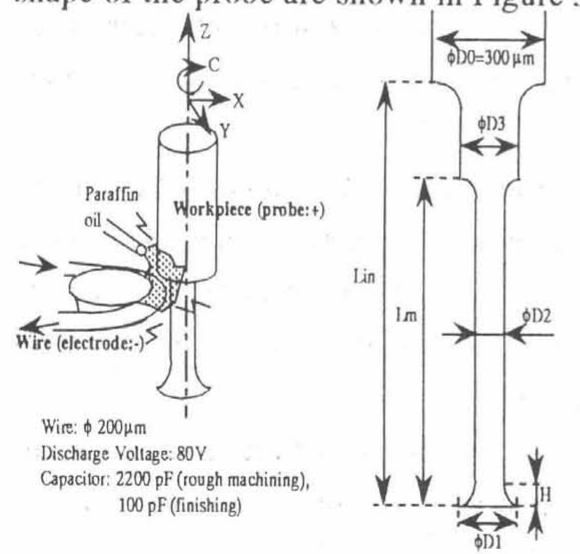

Pallern of probe $(\mu \mathrm{m})$ $\phi \mathrm{Dl}=150 \pm 5$, $\phi \mathrm{D} 2(\mathrm{~mm})=90$, $\phi D 3(\mathrm{~mm})=160$ $\operatorname{Lin}=1100, \mathrm{Lm}=850$, $\mathrm{H}=73.5$

Fig.3 Prototype of the fabricated microprobe.

The materials used were tungsten (W), molybdenum (Mo), hastelloy C-276, stainless steel (SUS316), tungsten carbide alloy (WC alloy), and platinum palladium (PtPd). Using these probes, we measured a sectional surface line of a $500-\mu \mathrm{m}$-long specimen (200 points at $2.5 \mu \mathrm{m}$ intervals). For probe vibration, a triangular wave of $100 \mathrm{~Hz}$ was selected.

Figure 4 shows the profile curves obtained using each probe. It is shown that the PtPd probe tracks a real surface most effectively, since PtPd is chemically stable against oxidation, and the data distribution is the narrowest. Rigid Mo and WC alloy are also regarded as stable materials for vibrating probes. In the case of hastelloy and SUS316, irregular peaks and troughs of about $2 \mu \mathrm{m}$ high are shown at different places during each surface scan.
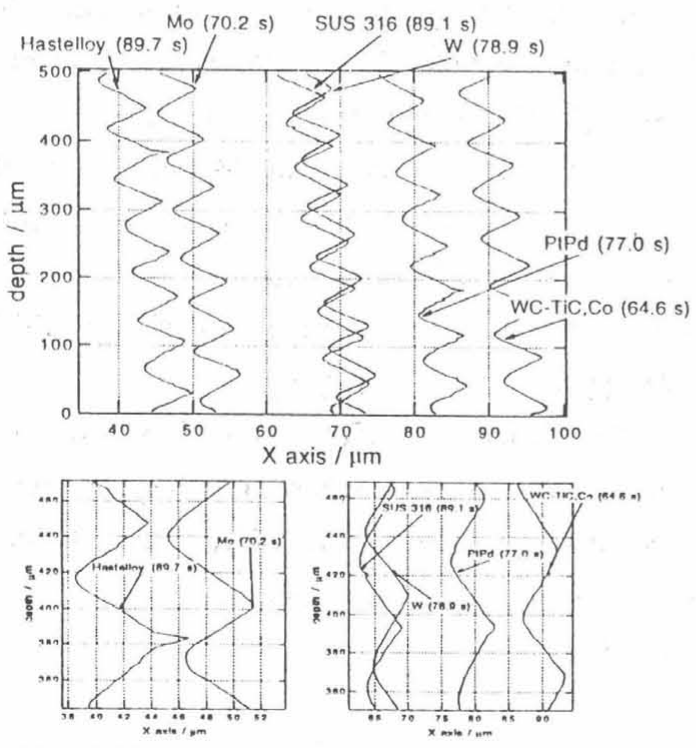

Fig. 4 Material dependence of measurement accuracy.

\section{4-2. Influence of vibration frequency and waveform}

Using three kinds of probes: Mo,WC alloy, and PtPd, the same surface as that described above was measured in order to optimize the conditions of vibration. Three frequencies, $50 \mathrm{~Hz}, 100 \mathrm{~Hz}$, and $200 \mathrm{~Hz}$, and three types of waveform, triangle(tri.), sine(sin.), and modulated triangle(mod.tri.) (the peak of the triangular wave is smoothed by a voltage limiter circuit), were tested.

The overall evaluation of stability and reproducibility obtained for each set of condition is shown in Table 1. Numbers in parentheses show the measurement time.

Table 1. Degree of accuracy given various sets of conditions.

CD process: $\mathrm{DF}=0.5(25 \mu \mathrm{m} \times 200$ points $)$

\begin{tabular}{|l||l|l|l|}
\hline PtPd & $100 \mathrm{~Hz}$ & $50 \mathrm{~Hz}$ & $200 \mathrm{~Hz}$ \\
\hline \hline Triangle & $\triangle(77.0 \mathrm{~s})$ & $\triangle(142.0 \mathrm{~s})$ & $X(42.6 \mathrm{~s})$ \\
\hline Sinusoidal & $(73.5 \mathrm{~s})$ & $\bigcirc(136.0 \mathrm{~s})$ & $X(49.8 \mathrm{~s})$ \\
\hline $\begin{array}{l}\text { Modulated } \\
\text { Triangle }\end{array}$ & $\bigcirc(69.8 \mathrm{~s})$ & $\bigcirc(129.7 \mathrm{~s})$ & $\searrow(52.8 \mathrm{~s})$ \\
\hline Molybdenum & $100 \mathrm{~Hz}$ & $50 \mathrm{~Hz}$ & $200 \mathrm{~Hz}$ \\
\hline \hline $\begin{array}{l}\text { Triangle } \\
\text { Sinusoidal }\end{array}$ & $\triangle(70.2 \mathrm{~s})$ & $\bigcirc(134.3 \mathrm{~s})$ & $\bigcirc(48.7 \mathrm{~s})$ \\
\hline $\begin{array}{l}\text { Modulated } \\
\text { Triangle }\end{array}$ & $\triangle(78.9 \mathrm{~s})$ & $\bigcirc(132.0 \mathrm{~s})$ & $\bigcirc(38.6 \mathrm{~s})$ \\
\hline \hline WC Alloy & $100 \mathrm{~Hz}$ & $50 \mathrm{~Hz}$ & $200 \mathrm{~Hz}$ \\
\hline \hline $\begin{array}{l}\text { Triangle } \\
\text { Sinusoidal }\end{array}$ & $\triangle(64.6 \mathrm{~s})$ & $\bigcirc(135.2 \mathrm{~s})$ & $\bigcirc(50.5 \mathrm{~s})$ \\
\hline $\begin{array}{l}\text { Modulated } \\
\text { Triangle }\end{array}$ & $\triangle(81.4 \mathrm{~s})$ & $\bigcirc(137.0 \mathrm{~s})$ & $\triangle(47.2 \mathrm{~s})$ \\
\hline
\end{tabular}

(O) :excellent(stable and small dispersion). $\bigcirc$ :good. $\triangle$ :fair(delay in measurement\& errors sometimes). $X$ :poor. $\mathbb{X}$ :bad.

Figure 5 shows the variations in stability under various vibration conditions. The influence of vibration waveform and frequency is compared for the three kinds of materials. WC alloy and Mo are rigid materials; therefore the first mode of the natural frequency is much higher than $200 \mathrm{~Hz}$. The contact 
force on the probe is negligible since it is smaller than $5 \sim 6 \mathrm{mN}$. For that reason, WC alloy and Mo are the most stable given the three conditions. In Figure 6, the difference among data due to the change of the waveform is plotted in a magnified scale. The difference is about $0.5 \mu \mathrm{m}$, except for $\mathrm{P} 1 \mathrm{Pd}$ at $200 \mathrm{~Hz}$. ( $\mathrm{PtPd}$ at $100 \mathrm{~Hz}$ incurs no problem.) This suggests that $\mathrm{PtPd}$ is not suitable for operation at higher frequencies.
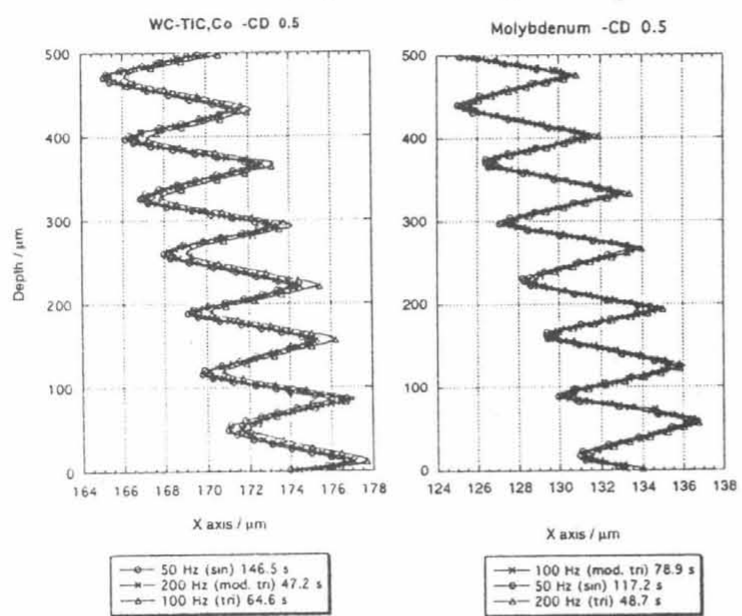

$\mathrm{X}$ axis $/ \mu \mathrm{m}$

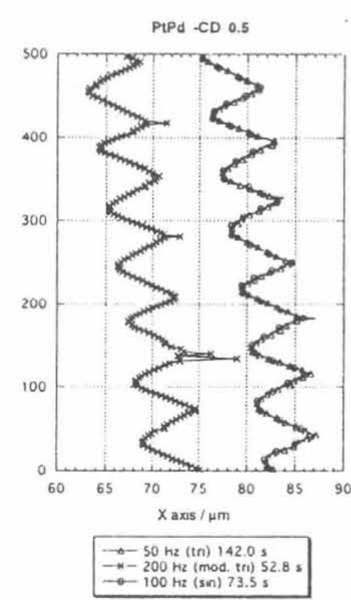

Fig.5 Influence of waveform and frequency.

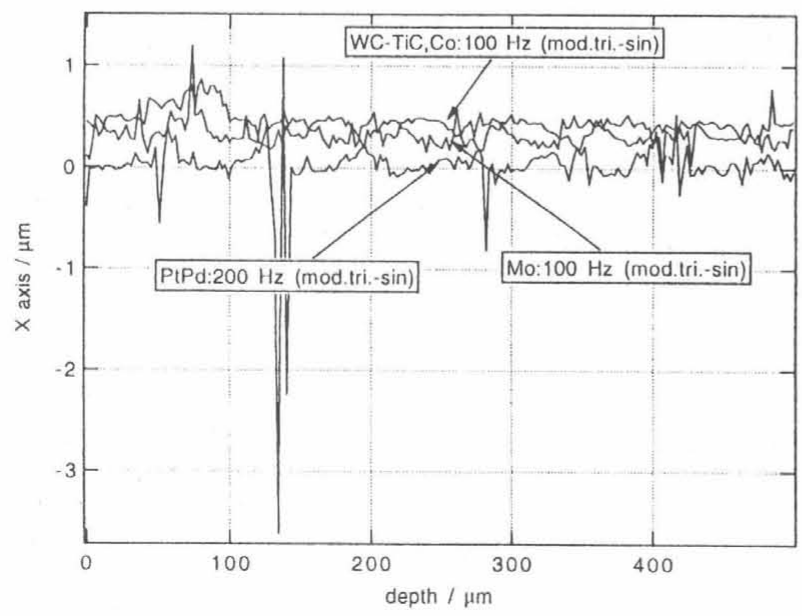

\section{CONCLUSION}

We developed the VS method to measure the inner dimensions of a microhole made by EDM machining. In this paper we present the high speed and the stability improvement of the VS method. To ensure good precision of measurement, the following has been shown.

1. The PtPd probe is the most stable probe in the frequency range of less than $200 \mathrm{~Hz}$ and is independent of measurement conditions. The most accurate measurements were obtained using a sine wave for the probe vibration.

2. Mo,WC alloy, and $\mathrm{W}$, which are rigid materials, are also suitable for use as probes up to the vibration frequency of $200 \mathrm{~Hz}$.

\section{REFERENCES}

[1]U.Bismayer, E.Brinksmeier, B.Gutter, H.Seibt, and C.Menz. "Measurement of subsurface damage in silicon wafers", Precision Engineering J. of ASPE., Vol. 16, No.2 (1994), pp.139 144

[2]H.Kawakatsu, Y.Hoshi, H.Kitano, and T.Higuchi. "Crystalline lattice for metrology and positioning control", Proc. IEEE Micro Electro Mechanical Systems Workshop, Nara,Japan,Jan.30 Feb.2, (1991), pp. 239 244

[3]T.Masuzawa, Y.Hamasaki, and M.Fujino. "Vibroscanning method for nondestructive measurement of small holes", Annals of the CIRP,42,1, (1993), pp.589 592

[4]Y.Sawamoto, T.Masuzawa, and M.Fujino. "High speed measurement of inner surface of microholes by vibroscanning method", Proc. of the Spring Assembly of JSPE, (1993), pp.763 764(in Japanese)

[5]B.J.Kim, T.Masuzawa, and M.Fujino. "High accuracy of vibroscanning method for microhole measurement - Influence of waveform of the probe (1st report)", Proc. of the Autumn Assembly of JSPE, (1994), pp.737 738(in Japanese)

[6]T.Masuzawa, M.Fujino, K.Kobayashi, and T.Suzuki. "Wire electrodischarge grinding for micromachining", Annals of the CIRP,34,1, (1985), pp.431 434pp.737 738(in Japanese)

Fig.6 Difference among the measured surface curve due to change of the waveform. 